\title{
Focal myocarditis in familial dystrophia myotonica
}

\author{
Alf Rausing \\ From the University Department of Pathology, University of Lund, Malmö General Hospital, \\ Malmö, Sweden
}

$A$ mother and her two sons with dystrophia myotonica are reported. All three patients had electrocardiographic abnormalities. The mother and one of the sons died. Necropsy revealed focal myocarditis. It is suggested that myocarditis is a manifestation of the natural history of 'dystrophia myotonica cordis', and that focal myocarditis generally may be a sign of metabolic or degenerative processes in the myocardium.

Dystrophia myotonica produces symptoms referable primarily to skeletal muscle, but many other organs may also be involved. Besides muscle dystrophy and myotonia the patients often have a special habitus and diverse metabolic abnormalities (Huff, Horton, and Lebovitz, 1967; Wochner et al., 1966). The condition seems to be inherited as a dominant character in the affected families. Cardiac muscle may also be involved. Pathological electrocardiographic findings are common (Örndahl et al., 1964), even in patients with no clinical signs of cardiac disease (Church, 1967). 'Dystrophia myotonica cordis' and the pathological changes found in the condition have been surveyed by Church (I967) and Thomson (1968). The findings are generally non-specific, and it is by no means certain that the changes are directly related to the muscular dystrophy even though they probably are.

This paper reports a family with a mother and two sons with dystrophia myotonica and pathological electrocardiographic findings. The mother and one son have died, and necropsy revealed focal myocarditis.

\section{Case reports}

The father appears healthy, and there are no known cases of muscular disease in earlier generations of the mother's family. The mother had had 4 children, 3 boys and I girl. One boy had died at 3 days of age from some unknown malformation. The girl has been operated upon because of cor triloculare biventriculare. She has no signs of muscular dystrophy and is now 27 years old. The other 2 boys have been affected with dystrophia myotonica. One of them now is 31 years

Received 4 May 1972. old and has been known to have had the disease since 23 years of age. His electrocardiograms have for the most part shown atrial flutter with varying block, but on a few occasions normal sinus rhythm. The history of the other boy is given below.

The mother was born in 1909. In 1956 she was admitted to hospital because of cerebral concussion. In I959 she was admitted again because of suspect postconcussion syndrome. The tendon reflexes were weak, but there were no other signs of muscular disease. The blood pressure was $100 / 60 \mathrm{mmHg}$ and adrenal insufficiency was suspected, but laboratory studies did not support this diagnosis. The diagnosis of dystrophia myotonica was confirmed in 1960. In the following years muscular wasting and myotonia successively became worse, and in 1968 the patient was admitted to hospital because of a respiratory infection.

Chest $x$-ray revealed nothing remarkable. The electrocardiogram showed sinus rhythm with an intraventricular conduction disorder and slight ST-T changes, and an acute myocardial lesion was suspected. The patient's condition deteriorated rapidly, she had chest pain and vomited and she died before further laboratory tests were performed.

Necropsy revealed bronchopneumonia and a conspicuous atrophy of the hypophysis, adrenal glands, and ovaries. The skeletal muscles had wasted and showed a microscopical picture compatible with dystrophia myotonica. The heart was atrophic and weighed only $195 \mathrm{~g}$; it was otherwise macroscopically normal. Eight blocks from different parts of the heart were examined microscopically. They showed changes of the type described as 'dystrophia myotonica cordis', that is an obvious variation in the thickness of the muscular fibres and enlarged hyperchromatic nuclei. In some places the interstitial connective tissue was increased. The sections from the left ventricle showed numerous foci of active myo- 
carditis consisting of lymphocytes and many histiocytes and polymorphonuclear and eosinophilic leucocytes. Some of the foci had a slightly granulomatous character, with collections of histiocytes surrounding a degenerating muscle fibre (Fig. I). The foci were numerous in the papillary muscles and also involved the endocardium.

The son who died was born in 1939. From the age of 20 he had complained of muscular weakness. When he was 27 , the diagnosis of dystrophia myotonica was confirmed. Besides typical muscular symptoms he had testicular atrophy and was slightly mentally retarded. He also had bilateral opacities of the lenses of the eyes and hypogammaglobulinaemia. The basal metabolic rate was -27 per cent as measured on several occasions. Lactic acid dehydrogenase in the serum was moderately raised, namely 630 units (upper limit of the normal range at the laboratory is 410 units). The rise was due mainly to an increase in isoenzyme fractions $I$ and 2. No further enzyme studies were undertaken. Chest $x$-ray was normal. Electrocardiograms on this occasion and later showed atrial flutter with varying block. He was not on any regular medication. In November 1971 the patient suddenly collapsed in the street. He had no acute illness at that time. On arrival in hospital he was found to have ventricular fibrillation which could not be converted and he soon died.

Necropsy showed obvious wasting of skeletal muscles and testicular atrophy, while the heart was macroscopically normal. Thirteen blocks of tissue from the heart ventricles were taken for microscopy. Three of them showed large foci of acute myocarditis. The cellular composition was the same as that of the lesions in the mother's heart. The muscle bundles were separated by cellular infiltration but seemed to be vital. In some places the picture left the same impression as that of the mother's heart, namely that collections of histiocytes were prominent around single degenerate muscle fibres. In many areas single muscle fibres showed abnormalities consisting of swelling or reduction in calibre and a widening and coarseness of the transverse bands (Fig. 2). In the papillary muscles, the endocardium was also affected (Fig. 3). In addition, many sections showed mild interstitial fibrosis.

\section{Discussion}

Tabulations of cardiac pathology in dystrophia myotonica do not mention focal myocarditis. A few published cases have shown mild interstitial fibrosis with a scanty lymphocytic infiltration. This may be a sign of earlier myocarditis. Foci of acute myocarditis, as described above, do not seem to have been noticed before in dystrophia myotonica. According to Thomson (1968), his case left the impression of a muscular degeneration without necrosis in the myocardium. The fibrosis and the variation in calibre of muscle

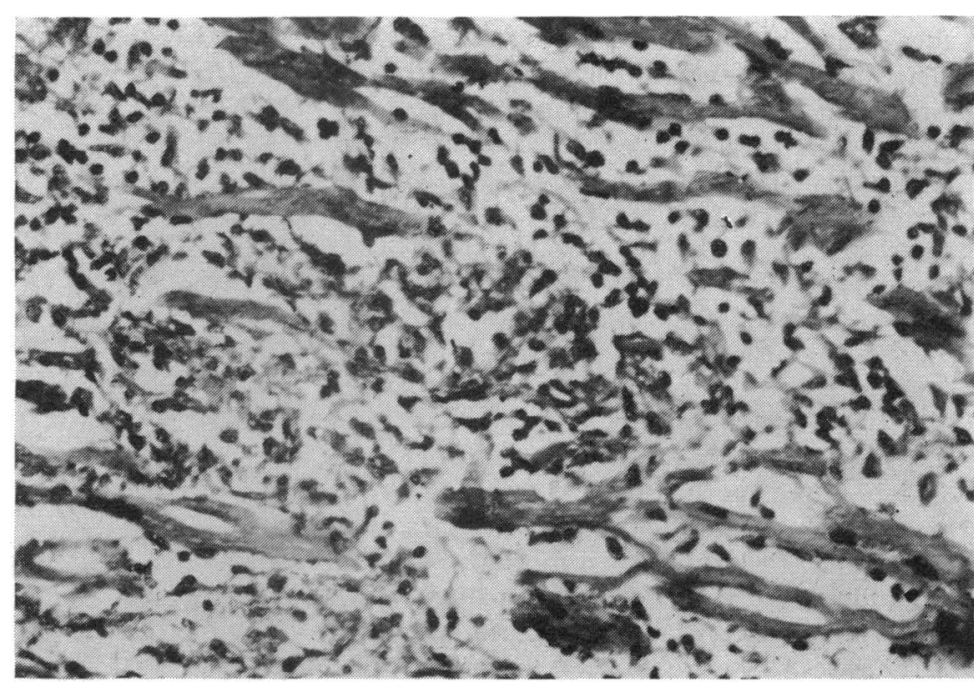

FI . I Photomicrograph of mother's heart.

Myocarditis with histiocytes around single

fibre. (Haematoxylin and eosin. $\times 318$.)

fibres and the nuclear hyperchromatism may all be signs of such degeneration. The abnormal internal architecture of some fibres is probably also a sign of a degenerative process. Bulloch, Davis, and Hara (1967) described electron microscopical irregularities of the Zbands in their case. The inflammatory changes without fibrosis in the cases described

FIG. 2 Photomicrograph of son's heart.

Focus of myocarditis and abnormal muscle

fibre with coarse transverse striation (arrow).

(Haematoxylin and eosin. $\times 318$.)

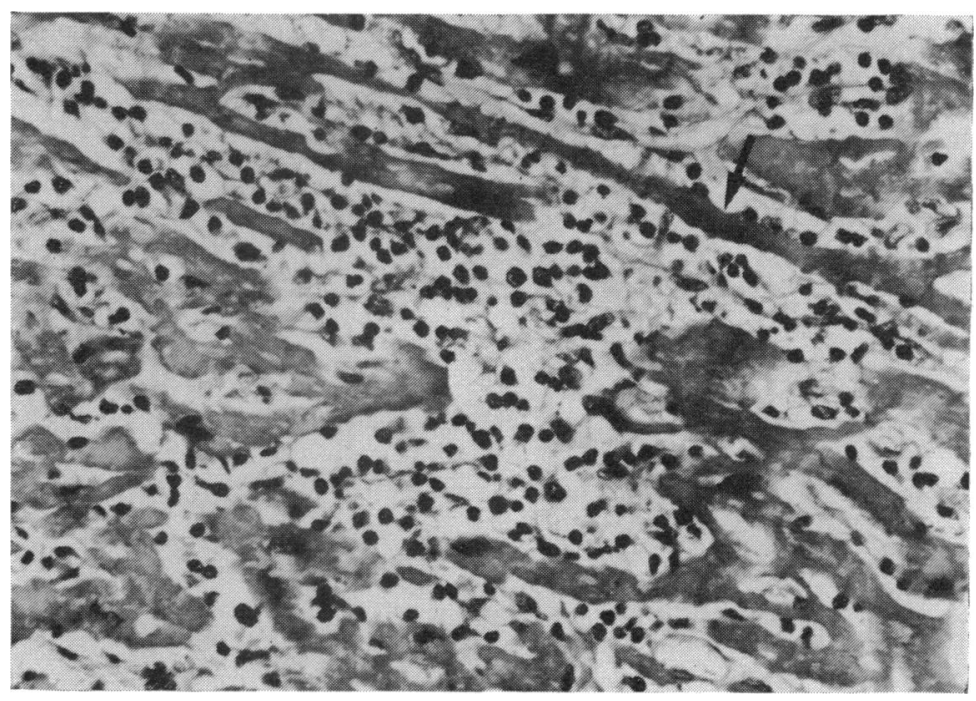


above may be a reaction to more active degeneration or single cell necrosis. As for the mother, it should be borne in mind that the myocarditis may have been secondary to the respiratory infection. The lesions are identical with those in the son, however, and he had no acute disease at the time of his collapse. It seems probable that both cases are manifestations of one and the same process, related to the basic disease of the patients. The myocarditis may be a component of the natural history of dystrophia myotonica but of focal and periodic nature and therefore difficult to detect. Extensive histological examination of the heart may be valuable in such cases. The lesions may be of forensic importance in cases of sudden, unexpected death in patients with dystrophia myotonica. As is illustrated by one of the cases reported above, it seems probable that the myocardial lesions can cause malignant arrhythmias. Treatment with corticosteroids might be worth a trial in cases of dystrophia myotonica with troublesome arrhythmia. The findings seem to be of interest also because focal myocarditis is generally an as yet largely unexplained disease. The possibility of metabolic and degenerative diseases should be kept in mind in other cases, too.

\section{References}

Bulloch, R. T., Davis, J. L., and Hara, M. (1967). Dystrophia myotonica with heart block. Archives of Pathology, 84, 130.

Church, S. C. (1967). The heart in myotonia atrophica. Archives of Internal Medicine, 119, 176.

Huff, T. A., Horton, E. S., and Lebovitz, H. E. (1967). Abnormal insulin secretion in myotonic dystrophy. New England fournal of Medicine, 277, 837.

Örndahl, G., Thulesius, O., Eneström, S., and Dehlin, O. (1964). The heart in myotonic disease. Acta Medica Scandinavica, 176, 479.

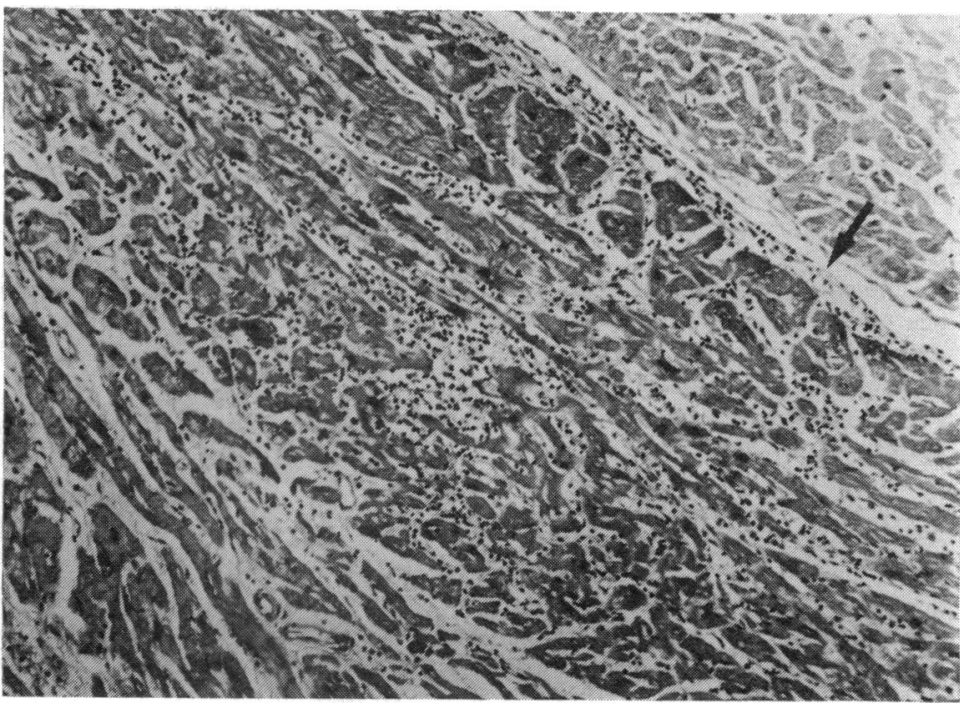

FIG. 3 Photomicrograph of son's heart.

Focus of myocarditis beneath the endocardium. Note cellular infiltration of endocardium (arrow). (Haematoxylin and eosin. $\times 90$.)

Thomson, A. M. P. (1968). Dystrophia cordis myotonica studied by serial histology of the pacemaker and conducting system. Fournal of Pathology and Bacteriology, 96, 285.

Wochner, R. D., Drews, G., Strober, W., and Waldmann, T. A. (1966). Accelerated breakdown of immunoglobulin $\mathrm{G}$ ( $\mathrm{IgG}$ ) in myotonic dystrophy: a hereditary error of immunoglobulin catabolism. fournal of Clinical Investigation, 45, $32 \mathrm{r}$.

Requests for reprints to Dr. Alf Rausing, Department of Pathology, Malmö General Hospital, S-2I4 or Malmö, Sweden. 